\title{
MAPEAMENTO DA PERCEPÇÃO DOCENTE SOBRE O PROCESSO DE AVALIAÇÃO DA CARREIRA DOCENTE DA UNICAMP
}

\section{Introdução:}

DOI: $10.20396 /$ sinteses.v0i7.11403

A carreira docente é orientada por avaliações. Na Unicamp a avaliação docente é estruturada no Projeto Qualidade. Seu trajeto sofreu mudanças de modelos, critérios, instâncias e foco. Essas mudanças estavam sintonizadas com a era da globalização e com os ideais neoliberalistas, que impeliam a Universidade a adotar um modelo de avaliação individualizada e centrada em critérios quantitativos, próprio de uma sociedade de controle. (DELEUZE, 1992; DEJOURS, 2013). A lógica produtivista vai implicando o mundo do trabalho e a saúde do trabalhador. Pretende-se discutir nesse trabalho, a partir da percepção dos docentes da Carreira MS da Unicamp, a importância do processo de avaliação para a carreira docente, como estão conformados seus critérios e se isso causa desconforto ao docente avaliado.

\section{Metodologia:}

Para compreender a percepção dos docentes sobre o sistema de avaliação no qual são periodicamente submetidos, foi aplicado, utilizando o Google Forms, um questionário contendo perguntas abertas e fechadas com aplicação da Escala de Likert. A coleta de dados ocorreu de 23.05 a 05.06.2019. Foram recebidos 249 questionários. A adesão foi voluntária com a garantia do anonimato. A pesquisa foi aprovada pelo Comitê de Ética? CEP/CHS.

\section{Resultados:}

A amostra da pesquisa mostrou-se significativa quando comparada com os dados globais da universidade (S-Integra). A grande maioria dos participantes (94,8\%) apontou que o processo de avaliação é importante e necessário para a carreira docente (figura 1). A percepção dos docentes respondentes aponta para uma forte concordância (cerca de $90 \%$ ) de que os critérios quantitativos recebem maior atenção pelo instrumento de avaliação. Pode-se inferir, sem generalização, que os participantes reconhecem que os critérios quantitativos são privilegiados pela instituição. Um expressivo número de docentes concordou, também, se sentir pressionado a atender indicadores de produção científica para ser bem avaliado $(90,4 \%)$. Buscamos entender se esse aspecto tinha correlação com a prevalência dos critérios quantitativos no instrumento de avaliação adotado. Encontramos uma forte convergência ao apurarmos que $82,7 \%$ do total dos respondentes concordaram ou concordaram totalmente com ambas afirmações (tabela 1). Nesse aspecto vale lembrar Bosi (2007) que pondera sobre a pressão que é exercida sobre os docentes para aumentar a geração de produtos traduzidos em aulas, orientações, publicações, projetos, patentes, entre outros.

\section{Considerações finais:}

Ainda que não se possa generalizar e extrapolar, podemos depreender a partir da percepção dos participantes que: ? A avaliação é necessária e importante para a carreira docente, o que valida sua continuidade; ? Os critérios quantitativos estão impressos na avalição docente; ? O expressivo sinal da pressão que os docentes sofrem para atender aos indicadores, provoca a necessária reflexão sobre o instrumento de avaliação para buscar alternativas que minimizem o sofrimento do avaliado.

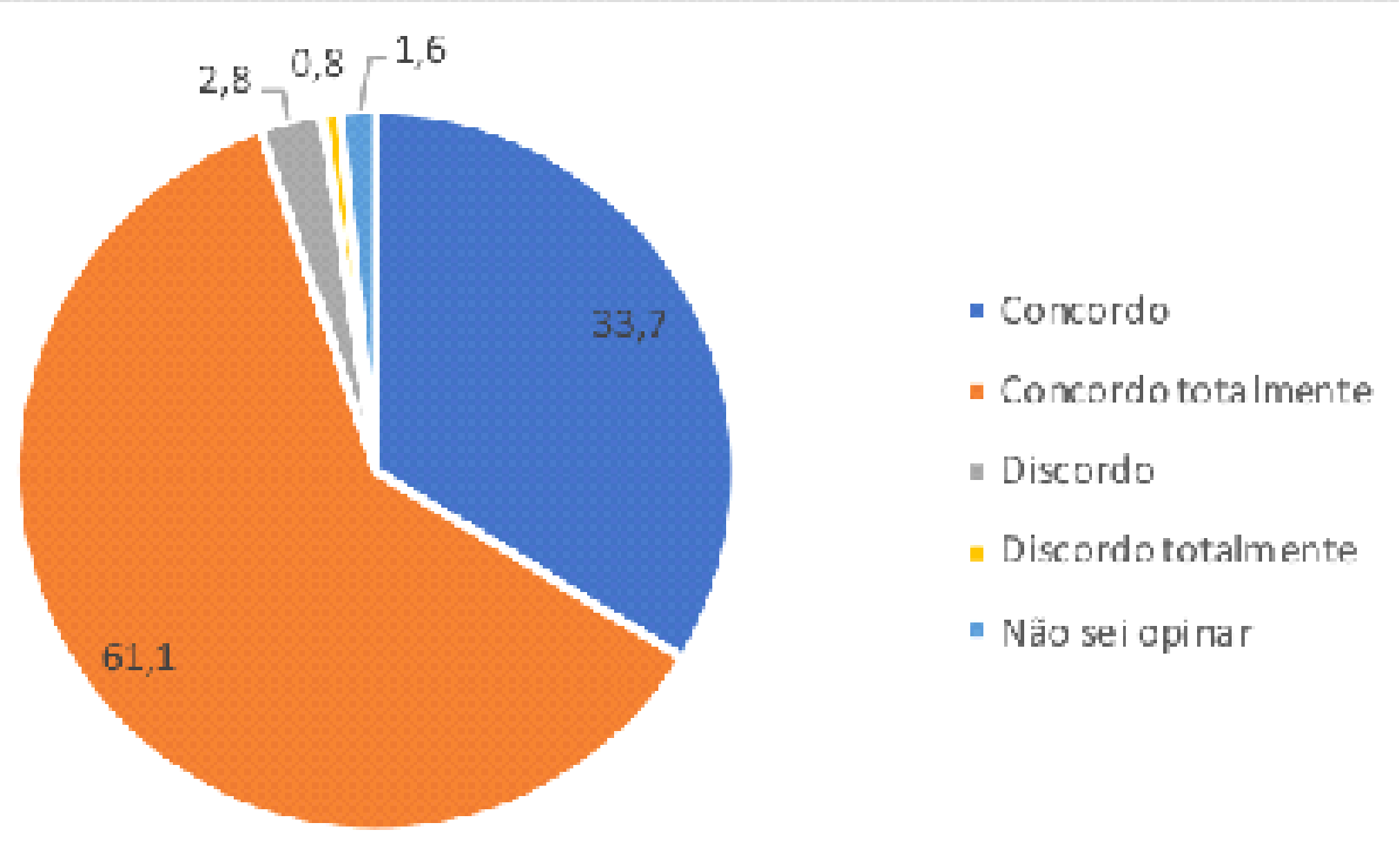

Fonte: Elaboração própria

Figura 1. Percepção sobre a importância do processo de avaliação para a carreira docente

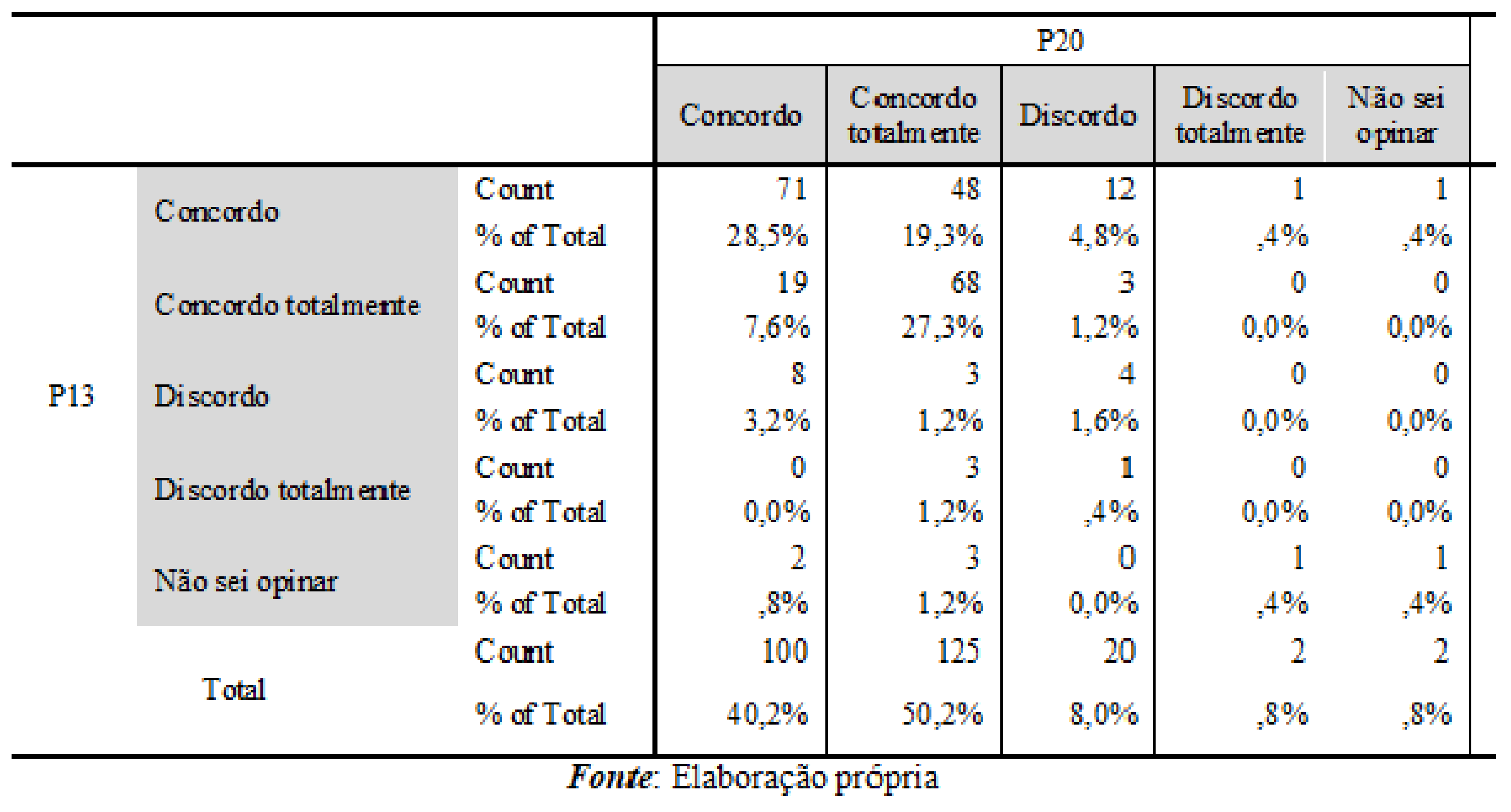

Tabela 1 ? Correlação entre a prevalência dos critérios quantitativos no instrumento de avaliação docente e se este se sente pressionado para atender indicadores de produção cientifica para ser bem avaliado

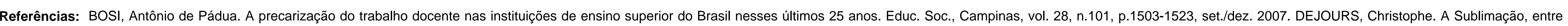

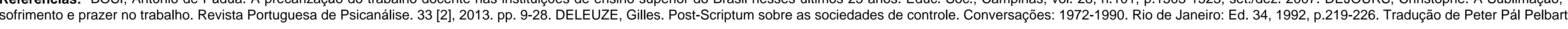

Agradecimentos: Registramos nossos agradecimentos aos docentes da Carreira do Magistério Superior (MS) da Universidade Estadual de Campinas (Unicamp) que, de forma voluntária, participaram da pesquisa 